\title{
Decreased expression of Beclin-1 is significantly associated with a poor prognosis in oral tongue squamous cell carcinoma
}

\author{
ZEDONG HU ${ }^{1,2^{*}}$, ZHAOMING ZHONG ${ }^{1 *}$, SHAOHUI HUANG ${ }^{3}$, HAOJIE WEN $^{1}$, \\ XUE CHEN ${ }^{1}$, HONGYING CHU ${ }^{1}$, QIULI LI ${ }^{4}$ and CHUANZHENG SUN ${ }^{1}$ \\ ${ }^{1}$ Department of Head and Neck Surgery, The Third Affiliated Hospital of Kunming Medical University; \\ ${ }^{2}$ Pain Department Ward, Yunnan Kungang Hospital (The Forth People's Hospital of Kunming), Kunming, Yunnan 650118; \\ ${ }^{3}$ Department of Oral and Maxillofacial Surgery, School of Stomatology, China Medical University, Shenyang, \\ Liaoning 110002; ${ }^{4}$ Department of Head and Neck Surgery, Sun Yat-sen University Cancer Center, \\ Guangzhou, Guangdong 510060, P.R. China
}

Received June 14, 2015; Accepted April 29, 2016

DOI: $10.3892 / \mathrm{mmr} .2016 .5437$

\begin{abstract}
The autophagy-related gene Beclin-1 is critical in the regulation of tumourigenesis and progression, but its role in oral tongue squamous cell carcinoma (OTSCC) has not yet been reported. This study aimed to investigate Beclin-1 expression and its significance in OTSCC. Beclin-1 expression was assessed by reverse transcription-quantitative polymerase chain reaction or western blot analysis in 14 OTSCC tissues and matched adjacent noncancerous tissues as well as in 5 OTSCC cell lines and a normal tongue epithelial cell line. Beclin-1 protein expression was examined by immunohistochemistry in 133 OTSCC specimens, and the correlation between Beclin-1 expression and clinicopathological features was investigated. Furthermore, MTT and colony formation assays were performed to investigate the effect of Beclin-1 on the proliferation and clonogenicity of OTSCC cells. It was demonstrated that Beclin-1 expression was significantly decreased in the majority of the 14 OTSCC tissues and the 5 OTSCC cell lines relative to the matched non-cancerous tissues and the normal tongue epithelial cell line, respectively. Immunohistochemistry analysis revealed that decreased Beclin-1 expression was significantly correlated with poor differentiation, lymph node metastasis, advanced clinical tumour-node-metastasis stage, and a poor prognosis in patients with OTSCC. The in vitro assays indicated that the overexpression of Beclin-1 significantly
\end{abstract}

Correspondence to: Dr Chuanzheng Sun, Department of Head and Neck Surgery, The Third Affiliated Hospital of Kunming Medical University, 519 Kunzhou Road, Kunming, Yunnan 650118, P.R. China

E-mail: scz008@126.com

${ }^{*}$ Contributed equally

Key words: oral cancer, tongue neoplasms, squamous cell carcinoma, Beclin-1, autophagy inhibits the proliferation and clonogenicity of OTSCC cells. These results demonstrate that Beclin-1 acts as a tumour suppressor in the development or progression of OTSCC and that Beclin-1 may represent a novel prognostic marker for patients with OTSCC.

\section{Introduction}

Oral carcinoma, which falls in the head and neck cancer category, represents one of the six most common types of cancer worldwide (1). Oral tongue squamous cell carcinoma (OTSCC) is the most common type of oral cancer, and the incidence of OTSCC has increased by $1.9 \%$ annually between 1975 and 2007, particularly among young adults (2). In the United States, an estimated 16,100 novel cases of OTSCC and 2,290 OTSCC-related fatalities are expected in 2014 (3). Even with the combination of surgery, chemotherapy and radiation, the overall five-year survival rate of OTSCC is only $50-60 \%$ (2). Thus, the identification of novel biomarkers is critical to OTSCC diagnosis and targeted treatment.

Autophagy is a bulk degradation process in which cytosolic misfolded proteins and damaged organelles are sequestered into autophagosomes and degraded by lysosomes to maintain organelle function and protein quality (4). Increased autophagy is a primary response to cellular stress that is an attempt to survive unfavourable conditions, such as nutrient depletion or hypoxia (5-7). Notably, autophagy is also involved in an array of biological and pathophysiological conditions, including tumourigenesis, immunity and embryonic development (8). Beclin-1 is the first identified mammalian autophagy gene (8). Previous studies have demonstrated that Beclin-1 is a haploinsufficient tumour suppressor; early embryonic lethality is observed in mice with biallelic loss of Beclin-1, and an increased rate of malignant tumours is observed in Beclin $1^{+/-}$mice $(9,10)$. Decreased Beclin-1 protein expression was confirmed in a series of human tumours, including hepatocellular carcinoma, ovarian carcinoma and laryngeal squamous cell carcinoma (11-13). By contrast, other studies have demonstrated that increased Beclin-1 expression is more frequently detected in colorectal 
carcinoma, gastric carcinoma, cutaneous squamous cell carcinoma and pancreatic ductal adenocarcinoma compared with the matched non-cancerous tissue of the same patient (14-18), which suggests that the function of Beclin-1 in tumourigenesis may vary among different tumour types $(19,20)$. Furthermore, whether Beclin-1 possesses autophagy-independent functions during tumourigenesis is now under investigation $(5,21)$.

OTSCC is a type of solid tumour; thus, OTSCC cancer cells often face nutrient deprivation and hypoxia, which leads to metabolic stress (2). Therefore, it was hypothesised that Beclin-1 is involved in the development and progression of OTSCC. The present study aimed to investigate Beclin-1 expression and its significance in OTSCC.

\section{Materials and methods}

Tissue specimens and patients. For reverse transcription-quantitiative polymerase chain reaction (RT-qPCR) and western blot analysis, 14 OTSCC tissues and matched adjacent non-cancerous tongue tissues (at a distance $>2 \mathrm{~cm}$ from the tumour) were collected from patients who underwent half-tongue resection between May and July 2010. In addition, 133 paraffin-embedded samples of OTSCC specimens were collected between January 2000 and December 2002 for immunohistochemical assay. All tissue samples were collected prior to chemotherapy or radiotherapy and were histologically and clinically diagnosed at the Third Affiliated Hospital of Kunming Medical University (Kunming, China). The tumour stage of each patient was classified according to the 2010 AJCC staging system (22). The median follow-up time of patients whose tissues were subjected to an immunohistochemical assay was 67 months at the time of analysis and ranged from 12 to 124 months. This study was approved by the Ethics Committee of the Third Affiliated Hospital of Kunming Medical University. The samples were collected after receiving informed consent from the patients.

$R T-q P C R$. The mRNA of OTSCC (NTEC1, TCA8113, TSCCA, SCC-9, SCC-25 and CAL-27 cells) and matched adjacent noncancerous tissues was purified using TRIzol Reagent (Invitrogen, Thermo Fisher Scientific, Inc., Waltham, MA, USA), and $2 \mu \mathrm{g}$ of each sample was reverse transcribed using a TIAN Script kit (Invitrogen, Thermo Fisher Scientific, Inc.). The following primers were used: Sense: 5'-GGTGTC TCTCGCAGATTCATC-3' and antisense: 5'-TCAGTCTTC GGCTGAGGTTCT-3' for Beclin-1; and sense: 5'-TGTTGC CATCAATGACCCCTT-3' and antisense 5'-CTCCACGAC GTACTCAGCG-3' for glyceraldehyde 3-phosphate dehydrogenase (GAPDH), which was used as an endogenous control. All reactions were run in triplicate in three independent experiments. All primers were synthesized by Invitrogen, Thermo Fisher Scientific, Inc. PCR reactions were performed on a PTC-200 PCR system (Bio-Rad Laboratories, Hercules, CA, USA) using the following cyclical procedure: $10 \mathrm{~min}$ at $94^{\circ} \mathrm{C}$, followed by 45 cycles of $15 \mathrm{sec}$ at $94^{\circ} \mathrm{C}, 30 \mathrm{sec}$ at $54^{\circ} \mathrm{C}, 30 \mathrm{sec}$ at $72^{\circ} \mathrm{C}$, and a final cycle at $72^{\circ} \mathrm{C}$ for $10 \mathrm{~min}$. For OTSCC cells, RT-qPCR and data collection were performed using an ABI PRISM 7900 HT sequence detection system (Applied Biosystems, Thermo Fisher Scientific, Inc.).
Western blot analysis. Cells (NTEC1, TCA8113, TSCCA, SCC-9, SCC-25 and CAL-27 cells, and patients paired tissue cells) were lysed with $1 \mathrm{X}$ sodium dodecyl sulphate (SDS) sample buffer $(62.5 \mathrm{mmol} / 1$ Tris- $\mathrm{HCl}, 2 \% \mathrm{SDS}, 10 \%$ glycerol and 5\% 2-mercaptoethanol). The protein concentration was determined using a bicinchoninic acid protein assay. A total of $25 \mu \mathrm{g}$ protein was separated electrophoretically in 9\% SDS-polyacrylamide gel electrophoresis, transferred to polyvinylidene fluoride membranes and incubated sequentially with primary rabbit monoclonal anti-Beclin-1 (cat. no. 2026-1; 1:4,000, Epitomics Inc., Burlingame, CA, USA), mouse monoclonal anti-LC3 (cat. no. AM1800a; 1:500, Abgent, San Diego, CA, USA), mouse monoclonal anti-p62/SQSTM1 (cat. no. sc-28359; 1:1,000, Santa Cruz Biotechnologies Inc., Santa Cruz, CA, USA), for $2 \mathrm{~h}$ at room temperature. After washing with TBS-T (Bio Basic Inc., Markham, ON, Canada), the membrane was incubated with a goat anti-mouse IgG (cat. no. 31430; 1:4,000) and goat-antirabbit IgG (cat. no. 31460; 1:3,000) secondary antibodies (Thermo Fisher Scientific, Inc. The membrane was washed and protein was detected using enhanced chemiluminescence reagent (Cell Signaling Technology, Beverly, MA, USA) and XAR film (Eastman Kodak Company, Rochester, NY, USA) according to the manufacturer's instructions. The membranes were then stripped and probed with an antiGAPDH mouse monoclonal antibody (1:3,000, Santa Cruz Biotechnology, Inc., Dallas, TX, USA) to confirm equal loading of the samples. The western blot bands were scanned and were analyzed using the Quantity One 4.6.7 program (Bio-Rad Laboratories).

Immunohistochemistry assay. In brief, paraffin-embedded OTSCC specimens were cut into 4- $\mu \mathrm{m}$ sections and incubated at $65^{\circ} \mathrm{C}$ for $30 \mathrm{~min}$. The sections were washed with xylene and rehydrated. Sections were submerged for 2 min into an EDTA buffer at $95^{\circ} \mathrm{C}$ and $90 \mathrm{kPa}$ for antigen retrieval and treated with $3 \%$ hydrogen peroxide in methanol, followed by incubation with $1 \%$ rabbit serum albumin (Zhongshan Golden Bridge Biotechnology, Co., Ltd.). The specimens were incubated overnight at $4^{\circ} \mathrm{C}$ with anti-Beclin-1 (1:200, Epitomics Inc.). For the negative control, the primary antibody was replaced with the non-immune rabbit IgG (Zhongshan Golden Bridge Biotechnology, Co., Ltd.). of the same isotype. Immunohistochemical staining to determine the expression of Beclin-1 revealed diffuse, fine, granular cytoplasmic staining under an XSZ-H microscope (Chongqing Optical \& Electrical Instrument Co., Ltd., Chongqing, China). The proportion of cells expressing Beclin-1 was scored as follows: 0, no expression; $1,0-25 \% ; 2,26-50 \%$; and 3,>50\%. The intensity of cell staining was scored as either 0 (no expression), 1 (yellow) or 2 (brown). The intensity score and proportion score were added to yield the total score, which was divided into no/low expression (0 to 2 ) or high expression (3 to 5$)$.

Cell lines and cell culture. The NTEC1 normal tongue epithelial cell line was established by culturing normal tongue squamous epithelium from a healthy patient in keratinocyte/serum-free medium (Invitrogen, Thermo Fisher Scientific, Inc.). This cell line was a gift from Professor 
Musheng Zeng (Sun Yat-sen University Cancer Centre, Guangzhou, China). CAL-27, SCC-25 and SCC-9 OTSCC cell lines were purchased from the American Type Culture Collection (Manassas, VA, USA) and Tca8113 and TSCCA cells were obtained from the Committee of the Type Culture Collection of the Chinese Academy of Sciences (Shanghai, China). With the exception of CAL-27, which was cultured in Dulbecco's modified Eagle's medium (Thermo Scientific, Inc.) supplemented with $10 \%$ foetal bovine serum (FBS, Thermo Fisher Scientific, Inc.), all cell lines were cultured in RPMI-1640 (Thermo Scientific, Inc.) supplemented with $5 \%$ FBS. All cells were cultured in penicillin $(100 \mathrm{U} / \mathrm{ml})$ and streptomycin $(100 \mathrm{U} / \mathrm{ml})$ at $37^{\circ} \mathrm{C}$ in a humidified $5 \% \mathrm{CO}_{2}$ incubator.

Plasmids and transfection. For the Beclin-1 expression plasmid, the full-length coding region of Beclin-1 cDNA was amplified by RT-qPCR, and the digested and purified PCR products were directly cloned into a lentivirus vehicle sinhcmv-mcs (r)-pre-cppt-IG (a gift from Professor Erik Zheng, Sun Yat-sen University Cancer Centre). The same method was used to construct a full-length LC3 expression plasmid using a pEGF vector (Invitrogen, Thermo Fisher Scientific, Inc.) to generate $\mathrm{pEGF}-\mathrm{C} 2-\mathrm{LC} 3$. The primer sequences of the full-length coding region were as follows: Sense: 5'-CGCGGA TCCATGGAAGGGTCTAAGACGT-3' and antisense: 5'-CGG AATTCTCATTTGTTATAAAATTGTGA for Beclin-1'; and sense: 5'-GAAGATCTTCATGCCCTCAGACCGGCC-3' and antisense: 5'-CGGAATTCTCAGAAGCCGAAGGTTTCC T-3' for LC3. All plasmids expressed enhanced green fluorescent protein (GFP) and were verified by sequencing. For the Beclin-1 overexpression plasmid, stably transfected cell lines were generated by lentivirus infection and selected using flow cytometry according to the manufacturer's instructions. The LC3 expression plasmid was transfected into OTSCC cell lines (TCA8113 and TSCCA) using Lipofectamine 2000 (Invitrogen, Thermo Fisher Scientific, Inc.) according to the manufacturer's instructions.

MTT assay. The cell growth and viability of the stable OTSCC cell lines (TCA8113 and TSCCA cells) were assessed by using an MTT assay. Approximately 3,000 cells/well were seeded in a 96-well plate for 6 duplicate wells with different drug concentrations. The MTT assay was performed on days 1-5. After incubation, $20 \mu \mathrm{l}$ of $5 \mathrm{mg} / \mathrm{ml}$ MTT (Sigma-Aldrich, St. Louis, MO, USA) was added to each well, followed by incubation for $4 \mathrm{~h}$. After discarding the medium carefully, formazan crystals were dissolved in $150 \mu$ l dimethyl sulfoxide. The optical density was measured with a microplate spectrophotometer (Bio-Rad Laboratories) at $490 \mathrm{~nm}$. Absorbance values were normalised to the percentage survival. Each experiment was performed in triplicate.

GFP LC3 puncta analysis. For analysis of GFP LC3 puncta in cells overexpressing Beclin-1 and control cells, the cells were observed under a fluorescence microscope (x400) and representative cells were selected and photographed. The number of GFP-LC3 puncta per cell was quantified, and presented as the mean \pm standard error of the mean from 50 randomly selected cells.
Colony formation assay. Cells (200/well; TCA8113 and TSCCA) were counted and plated in triplicate in six-well plates and were cultured with RPMI-1640 culture medium for $\sim 10$ days until the majority of the colonies had expanded to $>50$ cells. The plates were triple washed with cold phosphate-buffered saline, fixed in pre-chilled methanol for $10 \mathrm{~min}$, and dyed with $0.5 \%$ crystal violet for $5 \mathrm{~min}$ at room temperature. After washing to remove excess stain, the plates were photographed. Images were analysed using Image J 1.42 software (National Institutes of Health, Bethesda, MD, USA), according to the manufacturer's instructions. At least three independent experiments were performed for each assay.

Soft-agar anchorage-independent growth assay. For the bottom layer, six-well plates were coated with a $0.6 \%$ agar in medium supplemented with $20 \% \mathrm{FBS}$. For the top layer, 5,000 cells were prepared in $0.3 \%$ agar with $10 \%$ FBS and seeded in triplicate. The plates were then incubated at $37^{\circ} \mathrm{C}$ in a humidified $5 \% \mathrm{CO}_{2}$ incubator for two weeks until colonies had formed. Each experiment was repeated at least three times. Colonies were photographed (final magnification $\mathrm{x} 200$ ) under a phase-contrast microscope, and colonies $>50 \mathrm{~mm}$ in diameter were counted under a light microscope.

Statistical analysis. All statistical analyses were performed using SPSS 16.0 statistical software package (SPSS Inc., Chicago, IL, USA). The $\chi^{2}$ test for proportions was used to analyse the correlation between Beclin-1 expression and the clinicopathologic features of OTSCC. Survival curves were plotted using the Kaplan-Meier method and compared using the log-rank test. $\mathrm{P}<0.05$ was considered to indicate a statistically significant difference.

\section{Results}

Decreased expression of Beclin-1 in fresh OTSCC tissues and cell lines. The mRNA and protein expression of Beclin-1 were decreased in $78.6 \%$ of OTSCC tissues and cell lines relative to the matched adjacent noncancerous tissues and the NTEC1 normal tongue epithelial cell line, respectively (Fig. 1).

Correlation between Beclin-1 expression and the clinicopathological features and prognosis of patients with OTSCC. To further verify the expression of Beclin-1, an immunohistochemical assay was performed on 133 OTSCC specimens. As shown in Fig. 2, Beclin-1 protein was expressed in the cytoplasm. The decrease in Beclin-1 expression was closely correlated with poor differentiation, lymph node metastasis, and advanced clinical tumour-node-metastasis (TNM) stage of OTSCC (Table I). Notably, the five-year overall survival rate in the patients with no or low Beclin-1 expression was $47.5 \%$, significantly shorter than that of the patients with high Beclin-1 expression (70.8\%) (Fig. 3, $\mathrm{P}<0.01$ ).

Beclin-1 overexpression did not affect the level of autophagy but did inhibit cell proliferation. Beclin-1 is a pivotal gene in the process of autophagy. Therefore, the influence of Beclin-1 overexpression on autophagy upon starvation of OTSCC cells was investigated. As normal culture medium contains serum 
Table I. Correlation between Beclin-1 expression and clinicopathological features of the patients with OTSCC.

\begin{tabular}{|c|c|c|c|c|c|}
\hline \multirow[b]{2}{*}{ Characteristic } & \multirow[b]{2}{*}{$\mathrm{N}$} & \multicolumn{2}{|c|}{ Beclin-1 expression } & \multirow[b]{2}{*}{$\chi^{2}$} & \multirow[b]{2}{*}{ P-value } \\
\hline & & No/low (\%) & High (\%) & & \\
\hline Gender & & & & 0.170 & 0.680 \\
\hline Male & 74 & $34(45.9)$ & $40(54.1)$ & & \\
\hline Female & 59 & $25(42.4)$ & $34(57.6)$ & & \\
\hline Age (years) & & & & 2.844 & 0.092 \\
\hline$<50$ & 50 & $17(34.0)$ & $33(66.0)$ & & \\
\hline$\geq 50$ & 83 & $42(50.6)$ & $41(49.4)$ & & \\
\hline Clinical T phase & & & & 2.425 & 0.119 \\
\hline T1-2 & 117 & $49(41.9)$ & $68(58.1)$ & & \\
\hline T3-4 & 16 & $10(62.5)$ & $6(37.5)$ & & \\
\hline Clinical N phase & & & & 10.035 & 0.002 \\
\hline No & 99 & $36(36.4)$ & $63(63.6)$ & & \\
\hline $\mathrm{N} 1-2$ & 34 & $23(67.6)$ & $11(32.4)$ & & \\
\hline cTNM stage & & & & 8.718 & 0.003 \\
\hline I-II & 92 & $33(35.9)$ & $59(64.1)$ & & \\
\hline III-IV & 41 & $26(63.4)$ & $15(36.6)$ & & \\
\hline Histological differentiation & & & & 9.950 & 0.002 \\
\hline Well & 97 & $35(36.1)$ & $62(63.9)$ & & \\
\hline Moderately or poorly & 36 & $24(66.7)$ & $12(33.3)$ & & \\
\hline Recurrence & & & & 0.847 & 0.357 \\
\hline Yes & 44 & $22(50.0)$ & $22(50.0)$ & & \\
\hline No & 89 & 37 (41.6) & $52(58.4)$ & & \\
\hline
\end{tabular}

OTSCC, oral tongue squamous cell carcinoma; T, tumour; N, node; TNM, tumour-node-metastasis.

which may influence autophagy level, the cells were cultured in Earle's balanced salts (EBSS) to observe autophagy level. No significant difference in the expression levels of LC3-II and p62 was identified between the Beclin-1 overexpression cell line and the vehicle cell line subjected to starvation by culturing in EBSS for 1, 2, 4 or $8 \mathrm{~h}$. The number of GFP-LC3 puncta was also counted in at least 50 cells after transient transfection of pEGF-C2-LC3, and no significant difference was observed between the cells overexpressing Beclin-1 and the vehicle group $(12.66 \pm 0.32$ vs. $11.98 \pm 0.34 ; \mathrm{P}=0.7996)$ (Fig. 4). To determine whether Beclin-1 inhibited OTSCC cell proliferation, an MTT assay was performed, and the results suggested that Beclin-1 overexpression significantly inhibited the proliferation of OTSCC cell lines (Fig. 5A).

Beclin-1 inhibits the transformation of OTSCC cells lines. To further investigate whether Beclin-1 can inhibit the transformation of OTSCC cells, colony formation and soft-agar anchorage-independent growth assays were performed. In total, 200 cells were plated in triplicate wells of six-well plates. After 10 days of culture, the number of colonies formed by Beclin-1-expressing cells was significantly lower than that formed by negative-control cells or vehicle-control groups (Fig. 5B). Furthermore, Beclin-1-expressing cells formed significantly smaller and fewer colonies compared with the vector cells in the soft-agar assay (Fig. 5C).

\section{Discussion}

In the present study, Beclin-1 expression was decreased in $78.6 \%$ OTSCC tissues when compared with matched adjacent non-cancerous tissues, which implied that Beclin-1 may be important in carcinogenesis, consistent with other findings $(12,13,15-18,23,24)$. Similarly, it was observed that the mRNA and protein levels of Beclin-1 in a normal tongue squamous cell line were higher than those of OTSCC cell lines. Although Beclin-1 is an important autophagy gene, in the present study, Beclin-1 overexpression did not significantly change the autophagy level of OTSCC cells upon starvation. As shown for Atg6 in yeast, Beclin-1 may exhibit a non-autophagic role in specific cell types and environmental contexts $(5,25)$. For this reason, MTT, colony formation, and soft-agar anchorage-independent growth assays were conducted. These assays demonstrated that Beclin-1 overexpression significantly inhibits the proliferation and clonogenicity of OTSCC cells. Similarly, Koneri et al (26) reported that knockdown of Beclin-1 in a colon cancer cell line resulted in growth inhibition. In addition, Liang et al (9) also reported that Beclin-1 expression in the MCF-7 human breast carcinoma cell line significantly inhibited clonogenicity in vitro and tumourigenesis in nude mice. These results demonstrate that Beclin-1 can inhibit tumourigenesis by non-autophagic methods $(7,27)$. In the 

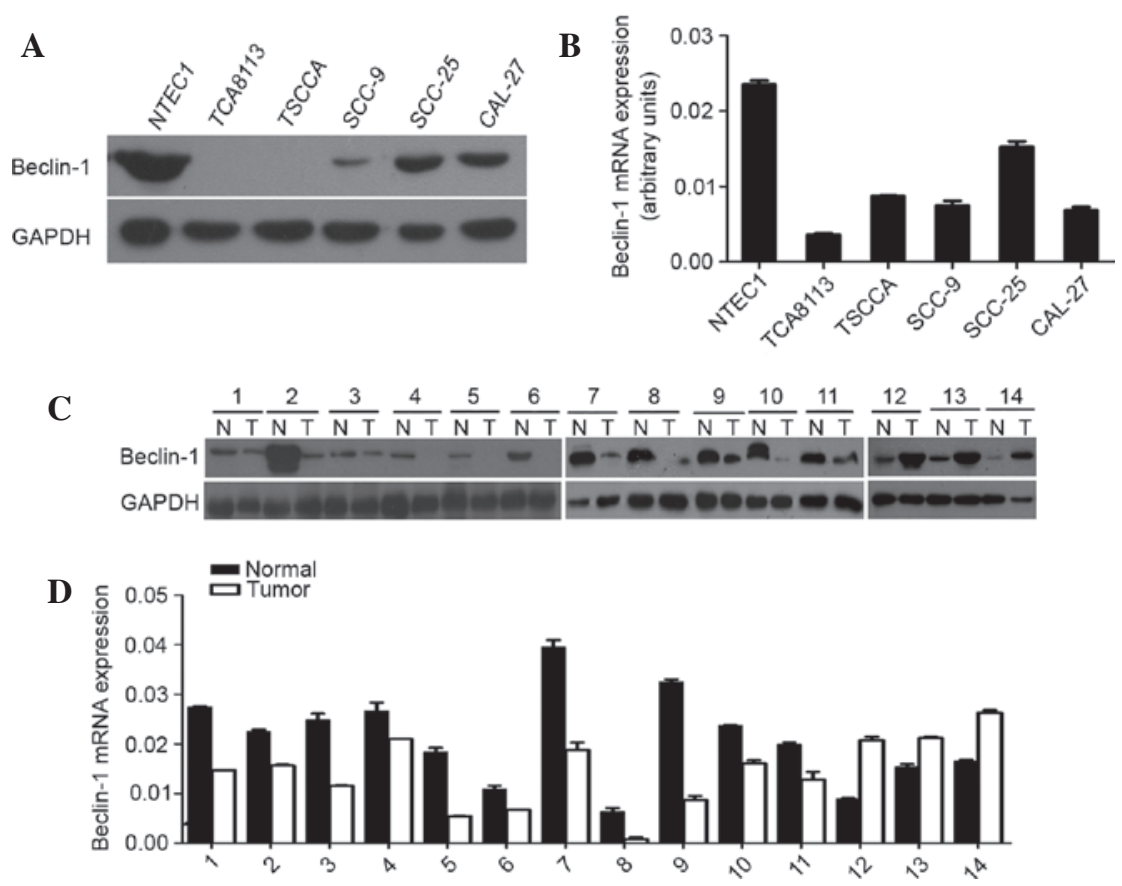

Figure 1. Beclin-1 expression in OTSCC tissues and cell lines. (A) Protein expression of Beclin-1 in 5 OTSCC cell lines and a normal tongue epithelial cell line (NTEC1) by western blot analysis. (B) mRNA expression of Beclin-1 in 5 OTSCC cell lines and a normal tongue epithelial cell line (NTEC1) by reverse transcription-quantitative polymerase chain reaction. (C) Protein expression of Beclin-1 in 14 paired OTSCC (T) tissues and adjacent noncancerous tissues (N) by western blot analysis. (D) mRNA expression of Beclin-1 in 14 paired OTSCC (T) tissues and adjacent noncancerous tissues (N) by reverse transcription-quantitative polymerase chain reaction. OTSCC, oral tongue squamous cell carcinoma.

A

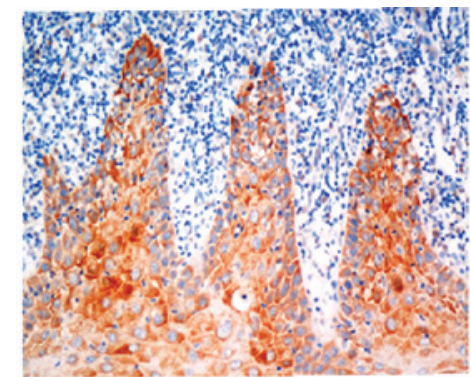

C

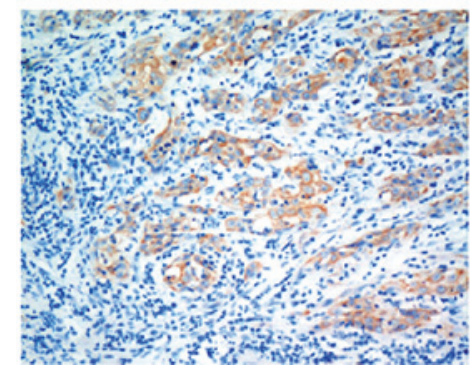

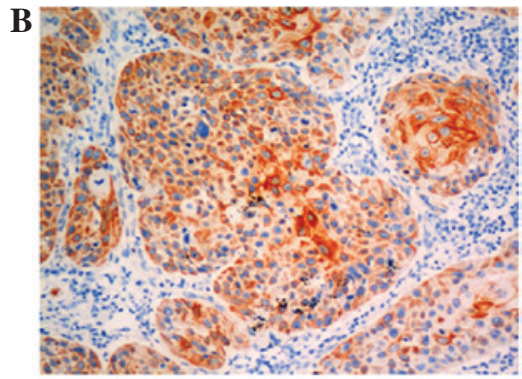

D

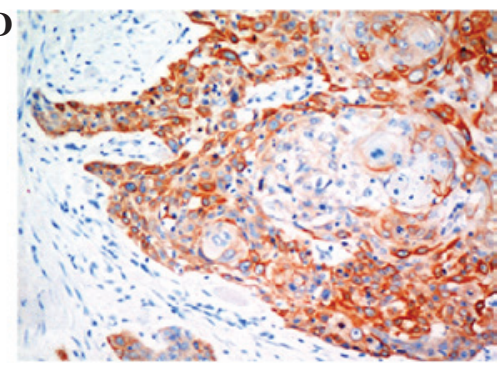

Figure 2. Protein expression of Beclin-1 by immunohistochemistry (magnification, x200). (A) Beclin-1 expression in the normal tongue epithelium. (B) Intermediate expression of Beclin-1 in OTSCC tissue. (C) Low expression of Beclin-1 in OTSCC tissue. (D) High expression of Beclin-1 in OTSCC tissue. OTSCC, oral tongue squamous cell carcinoma.

present study, decreased Beclin-1 expression by immunohistochemistry was associated with poor differentiation, lymph node metastasis, and advanced clinical TNM stage of OTSCC, indicating that Beclin-1 may be involved in the tumourigenesis and progression, consistent with the results of several studies $(8,13,15,18,27-29)$. Accordingly, increased Beclin-1 expression was associated with the absence of lymphatic invasion and a low rate of distant metastasis in pancreatic ductal adenocarcinoma or laryngeal squamous cell carcinoma $(11,18)$, reduced cell proliferation in glioma (30), and reduced invasiveness and metastasis of oesophageal squamous cell carcinoma (31). However, the autophagy-related genes are also known to exhibit conflicting roles in tumourigenesis $(7,25,32)$. Consistent with this dual role, certain studies reports have demonstrated that the increased expression of Beclin-1 is correlated with poor differentiation of ovarian carcinoma (8) and endometrial adenocarcinomas (33). Similarly, the prognostic relevance of 


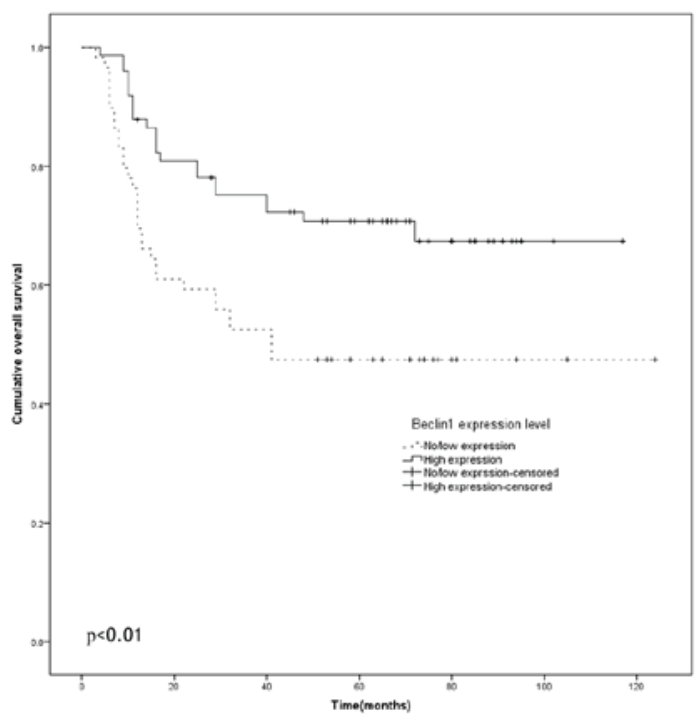

Figure 3. Overall survival curves of patients with oral tongue squamous cell carcinoma subdivided according to Beclin-1 protein expression.
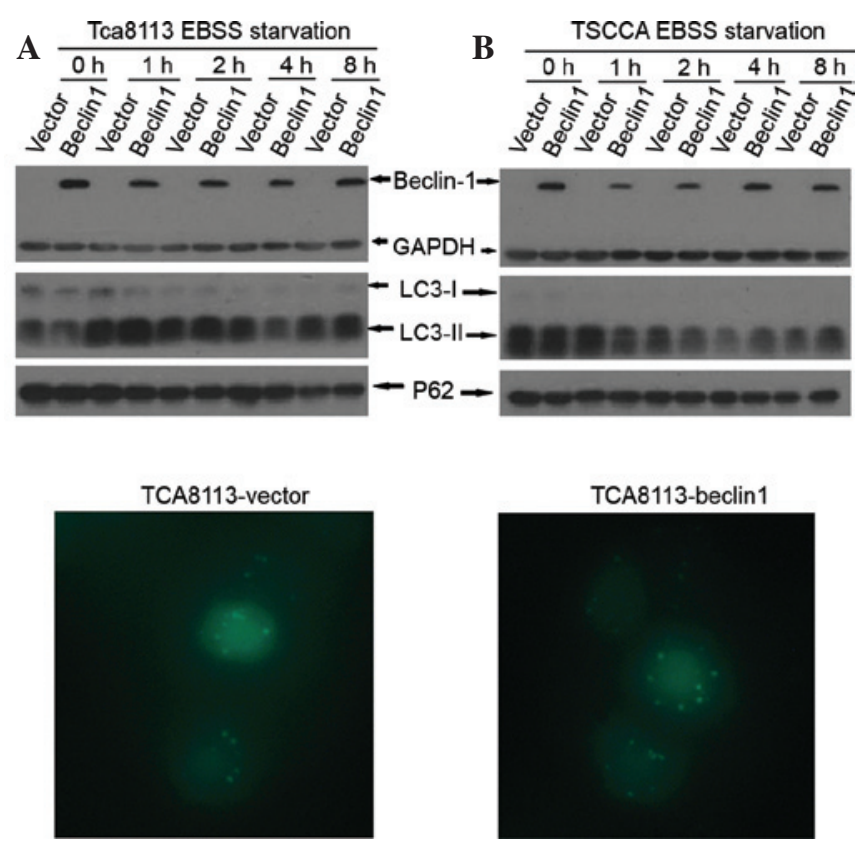

Figure 4. Beclin-1 overexpression did not change the level of autophagy in OTSCC cells upon starvation. (A) No significant difference in the expression level of LC3-II or p62 occurred between the Beclin-1-expressing cell line and the vehicle group detected upon starvation by culturing in EBSS medium for $1,2,4$ or $8 \mathrm{~h}$. (B) The number of GFP-LC3 puncta was counted in at least 50 cells after transient transfection with pEGF-C2-LC3, and no significant difference was detected between the two groups. EBSS, Earle's balanced salt solution; OTSCC, oral tongue squamous cell carcinoma.

Beclin-1 expression has been discussed in various malignancies, but the results are controversial $(8-15,18,28,31,33-35)$. In the present study, a positive link between the Beclin-1 expression level and favourable survival was revealed in OTSCC, which was similar to the results in several other types of cancer, including gastric carcinoma $(14,15)$, pancreatic ductal adenocarcinoma (18), intrahepatic cholangiocellular carcinoma (28), hepatocellular carcinoma (12), oesophageal
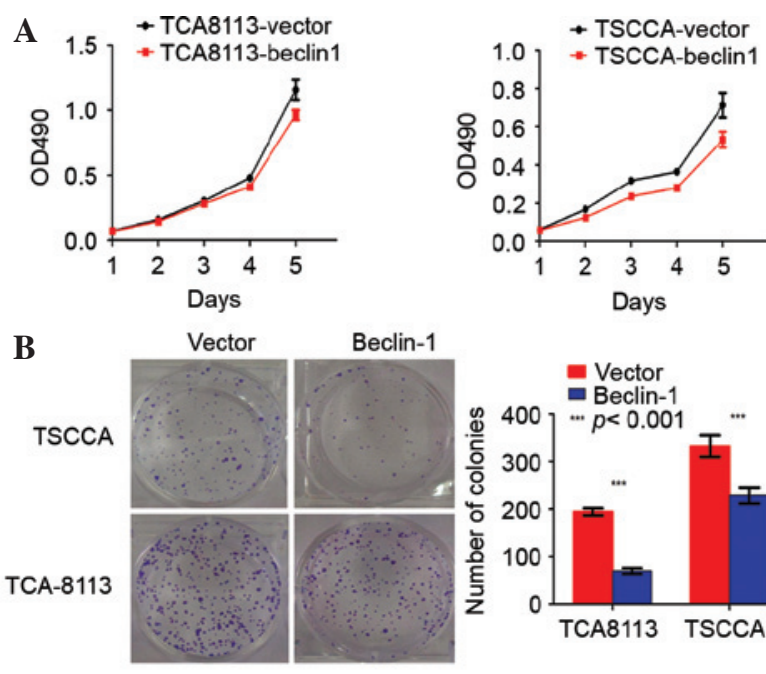

Beclin-1
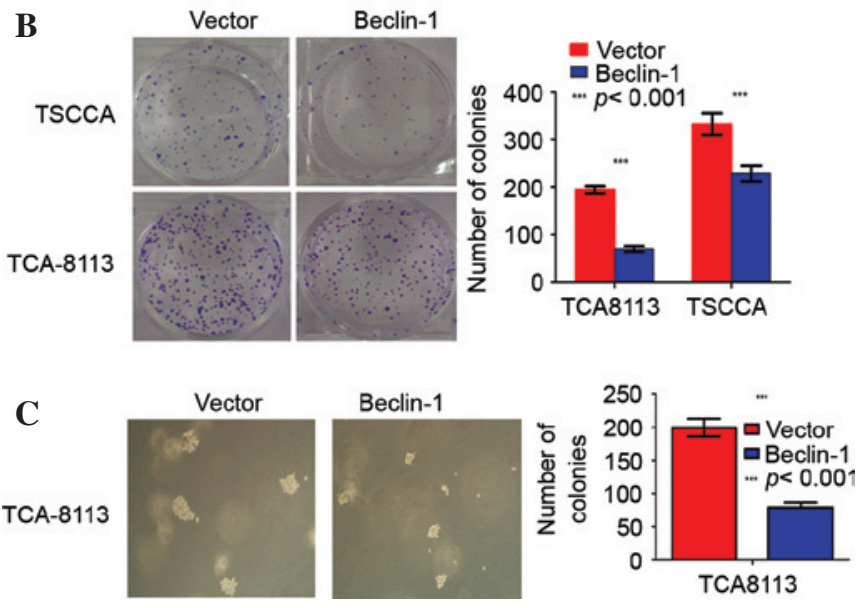

Figure 5. Beclin-1 overexpression inhibits the proliferation and transformation of OTSCC cells. (A) Beclin-1 inhibits the cell proliferation of OTSCC as demonstrated by an MTT assay. (B) Beclin-1 inhibits the transformation of OTSCC cells as demonstrated by a colony formation assay. (C) Beclin-1 inhibits the transformation of OTSCC cells as demonstrated by the soft-agar anchorage-independent growth assay. OTSCC, oral tongue squamous cell carcinoma. Magnification, $\mathrm{x} 200 .{ }^{* * *} \mathrm{P}<0.001$ compared with the control.

squamous cell carcinoma (31), colon carcinoma (10), lymphoma (35), ovarian carcinoma (13), and laryngeal squamous cell carcinoma (11). By contrast, several studies have reported that patients with lower Beclin-1 expression exhibit a significant overall survival advantage compared with those with higher expression in nasopharyngeal carcinoma (34), ovarian carcinoma (8) and endometrial adenocarcinoma (33). These discrepant results indicate that Beclin-1 maybe perform different functions in different carcinomas (36), and the methodological differences in immunohistochemistry evaluation and the small sample size may represent additional reasons for these discrepant findings.

In conclusion, the present study demonstrated that decreased Beclin-1 expression is closely associated with poor differentiation and advanced TNM stage in OTSCC, and that Beclin-1 overexpression inhibited the proliferation and clonogenic formation of OTSCC cells. This indicated that Beclin-1 functioned as a tumour suppressor in OTSCC at least partly by non-autophagic mechanisms. Beclin-1 expression may therefore represent a favourable prognostic marker or a novel therapeutic target for OTSCC.

\section{Acknowledgements}

The present study was supported by grants from the National Natural Science Foundation of China (grant nos. 30960444 and 81260402), and Special Foundation of High Levels of Health Technical Personnel Training in Yunnan Province (grant no. D-201243). 


\section{References}

1. Kapoor V, Paliwal D, Baskar Singh S, Mohanti BK and Das SN: Deregulation of Beclin 1 in patients with tobacco-related oral squamous cell carcinoma. Biochem Biophys Res Commun 422: 764-769, 2012

2. Zhang J, Wen HJ, Guo ZM, Zeng MS, Li MZ, Jiang YE, He XG and Sun CZ: TRB3 overexpression due to endoplasmic reticulum stress inhibits AKT kinase activation of tongue squamous cell carcinoma. Oral Oncol 47: 934-939, 2011.

3. Siegel R, Ma J, Zou Z and Jemal A: Cancer statistics, 2014. CA Cancer J Clin 64: 9-29, 2014.

4. Maejima Y, Kyoi S, Zhai P, Liu T, Li H, Ivessa A, Sciarretta S, Del Re DP, Zablocki DK, Hsu CP, et al: Mst1 inhibits autophagy by promoting the interaction between Beclin1 and Bcl-2. Nat Med 19: 1478-1488, 2013

5. Wirawan E, Lippens S, Vanden Berghe T, Romagnoli A, Fimia GM, Piacentini M and Vandenabeele P: Beclin1: A role in membrane dynamics and beyond. Autophagy 8: 6-17, 2012.

6. Gurkar AU, Chu K, Raj L, Bouley R, Lee SH, Kim YB, Dunn SE, Mandinova A and Lee SW: Identification of ROCK1 kinase as a critical regulator of Beclin1-mediated autophagy during metabolic stress. Nat Commun 4: 2189, 2013.

7. Shin JY, Hong SH, Kang B, Minai-Tehrani A and Cho MH: Overexpression of beclin1 induced autophagy and apoptosis in lungs of K-rasLA1 mice. Lung Cancer 81: 362-370, 2013.

8. Zhao Y, Chen S, Gou WF, Xiao LJ, Takano Y and Zheng HC: Aberrant Beclin 1 expression is closely linked to carcinogenesis, differentiation, progression and prognosis of ovarian epithelial carcinoma. Tumour Biol 35: 1955-1964, 2014.

9. Huang L, Wang S, Li SS and Yang XM: Prognostic significance of Beclin-1 expression in laryngeal squamous cell carcinoma. Pathol Oncol Res 19: 771-777, 2013.

10. Shi YH, Ding ZB, Zhou J, Qiu SJ and Fan J: Prognositc significance of Beclin 1-dependent apoptotic activity in hepatocellular carcinoma. Autophagy 5: 380-382, 2009.

11. Lin HX, Qiu HJ, Zeng F, Rao HL, Yang GF, Kung HF, Zhu XF, Zeng YX, Cai MY and Xie D: Decreased expression of Beclin 1 correlates closely with Bcl-xL expression and poor prognosis of ovarian carcinoma. PLoS One 8: e60516, 2013.

12. Yu M, Gou WF, Zhao S, Xiao LJ, Mao XY, Xing YN Takahashi H, Takano Y and Zheng HC: Beclin 1 expression is an independent prognostic factor for gastric carcinomas. Tumour Biol 34: 1071-1083, 2013.

13. Chen YB, Hou JH, Feng XY, Chen S, Zhou ZW, Zhang XS and Cai MY: Decreased expression of Beclin 1 correlates with a metastatic phenotypic feature and adverse prognosis of gastric carcinoma. J Surg Oncol 105: 542-547, 2012.

14. Ahn CH, Jeong EG, Lee JW, Kim MS, Kim SH, Kim SS, Yoo NJ and Lee SH: Expression of beclin-1, an autophagy-related protein, in gastric and colorectal cancers. APMIS 115: 1344-1349, 2007.

15. Okura R and Nakamura M: Overexpression of autophagy-related beclin-1 in cutaneous squamous cell carcinoma with lymph-node metastasis. Eur J Dermatol 21: 1002-1003, 2011.

16. Kim HS, Lee SH, Do SI, Lim SJ, Park YK and Kim YW: Clinicopathologic correlation of beclin-1 expression in pancreatic ductal adenocarcinoma. Pathol Res Pract 207: 247-252, 2011

17. Chen N and Karantza-Wadsworth V: Role and regulation of autophagy in cancer. Biochim Biophys Acta 1793: 1516-1523, 2009.

18. Marino G, Salvador-Montoliu N, Fueyo A, Knecht E, Mizushima $\mathrm{N}$ and López-Otín C: Tissue-specific autophagy alterations and increased tumorigenesis in mice deficient in Atg4C/autophagin-3. J Biol Chem 282: 18573-18583, 2007.

19. Liu J, Xia H, Kim M, Xu L, Li Y, Zhang L, Cai Y, Norberg HV, Zhang T, Furuya T, et al: Beclin 1 controls the levels of p53 by regulating the deubiquitination activity of USP10 and USP13. Cell 147: 223-234, 2011.
20. Edge SB, Byrd DR, Compton CC, Fritz AG, Greene FL and Trotti A, (eds): AJCC Cancer Staging Manual, 7th edition. Springer, New York, 2010.

21. Huang X, Bai HM, Chen L, Li B and Lu YC: Reduced expression of LC3B-II and Beclin 1 in glioblastoma multiforme indicates a down-regulated autophagic capacity that relates to the progression of astrocytic tumors. J Clin Neurosci 17: 1515-1519, 2010.

22. Jiang ZF, Shao LJ, Wang WM, Yan XB and Liu RY: Decreased expression of Beclin-1 and LC3 in human lung cancer. Mol Biol Rep 39: 259-267, 2012

23. Sun Y, Liu JH, Jin L, Lin SM, Yang Y, Sui YX and Shi H: Over-expression of the Beclin 1 gene upregulates chemosensitivity to anti-cancer drugs by enhancing therapy-induced apoptosis in cervix squamous carcinoma CaSki cells. Cancer Lett 294: 204-210, 2010.

24. Koneri K, Goi T, Hirono Y, Katayama K and Yamaguchi A: Beclin 1 gene inhibits tumor growth in colon cancer cell lines. Anticancer Res 27: 1453-1457, 2007.

25. Liang XH, Jackson S, Seaman M, Brown K, Kempkes B, Hibshoosh $\mathrm{H}$ and Levine B: Induction of autophagy and inhibition of tumorigenesis by beclin 1. Nature 402: 672-676, 1999.

26. Won KY, Kim GY, Lim SJ and Kim YW: Decreased Beclin-1 expression is correlated with the growth of the primary tumor in patients with squamous cell carcinoma and adenocarcinoma of the lung. Hum Pathol 43: 62-68, 2012.

27. Dong LW, Hou YJ, Tan YX, Tang L, Pan YF, Wang M and Wang HY: Prognostic significance of Beclin 1 in intrahepatic cholangiocellular carcinoma. Autophagy 7: 1222-1229, 2011.

28. Wang $\mathrm{ZH}, \mathrm{Xu} \mathrm{L}$, Wang $\mathrm{Y}$, Cao MQ, Li L and Bai T: Clinicopathologic correlations between human papillomavirus 16 infection and Beclin 1 expression in human cervical cancer. Int J Gynecol Pathol 30: 400-406, 2011.

29. Pirtoli L, Cevenini G, Tini P, Vannini M, Oliveri G, Marsili S, Mourmouras V, Rubino G and Miracco C: The prognostic role of Beclin 1 protein expression in high-grade gliomas. Autophagy 5: 930-936, 2009.

30. Chen Y, Lu Y, Lu C and Zhang L: Beclin-1 expression is a predictor of clinical outcome in patients with esophageal squamous cell carcinoma and correlated to hypoxia-inducible factor (HIF)-1alpha expression. Pathol Oncol Res 15: 487-493, 2009.

31. Mathew R, Karantza-Wadsworth V and White E: Role of autophagy in cancer. Nat Rev Cancer 7: 961-967, 2007.

32. Giatromanolaki A, Koukourakis MI, Koutsopoulos A, Chloropoulou P, Liberis V and Sivridis E: High beclin 1 expression defines a poor prognosis in endometrial adenocarcinomas. Gynecol Oncol 123: 147-151, 2011

33. Wan XB, Fan XJ, Chen MY, Xiang J, Huang PY, Guo L, Wu XY, $\mathrm{Xu} \mathrm{J}$, Long ZJ, Zhao Y, et al: Elevated Beclin 1 expression is correlated with HIF-1 alpha in predicting poor prognosis of nasopharyngeal carcinoma. Autophagy 6: 395-404, 2010.

34. Koukourakis MI, Giatromanolaki A, Sivridis E, Pitiakoudis M, Gatter KC and Harris AL: Beclin 1 over- and underexpression in colorectal cancer: Distinct patterns relate to prognosis and tumour hypoxia. Br J Cancer 103: 1209-1214, 2010.

35. Huang JJ, Li HR, Huang Y, Jiang WQ, Xu RH, Huang HQ, Lv Y, Xia ZJ, Zhu XF, Lin TY and Li ZM: Beclin 1 expression: A predictor of prognosis in patients with extranodal natural killer T-cell lymphoma, nasal type. Autophagy 6: 777-783, 2010.

36. Mathew R, Kongara S, Beaudoin B, Karp CM, Bray K, Degenhardt K, Chen G, Jin S and White E: Autophagy suppresses tumor progression by limiting chromosomal instability. Genes Dev 21: 1367-1381, 2007. 